\title{
Effect of formaldehyde treated concentrate, urea and soybean meal on proximate analysis and feed intake in lactating cows
}

\author{
N.S. CHORE, S.D. CHAVAN, R. R. SHELKE AND S. P. NAGE
}

Author for Corresponding -

\section{R. R. SHELKE}

Department of Animal

Husbandry and Dairy Science,

College of Agriculture, Dr

Panjabrao Deshmukh Krishi

Vidyapeeth, AKOLA (M.S.) INDIA

See end of the article for

Coopted authors'
ABSTRACT...... Present investigation entitled "effect of formaldehyde treated concentrate, urea and soybean meal on proximate analysis and feed intake in lactating cows" was undertaken at Department of Animal Husbandry and Dairy Science, Dr. Panjabrao Deshmukh Krishi Vidyapeeth, Akola. Feeding of 1.5 per cent formaldehyde treated 70:30 sugras : SBM concentrate mixture with 2 per cent added urea diet to lactating cows $\left(\mathrm{T}_{3}\right)$ was evaluated in relation to sugras untreated ration $\left(\mathrm{T}_{1}\right)$. SBM contained 49.50 and $\mathrm{CP}$ against a content of 17.60 per cent $\mathrm{CP}$ in sugras concentrate. The untreated 70:30 mixture had 27.47 per cent $\mathrm{CP}$ and 1.5 per cent $\mathrm{HCHO}$ treatment to mixture did not influence the proximate principles, though there was slight decrease in the constituents of mixture. The average DMI was 7.97, 7.78, 7.85, 7.01 and 7.21 $\mathrm{kg} /$ cow on feeding control $\left(\mathrm{T}_{1}\right), 70: 30$ untreated $\left(\mathrm{T}_{2}\right)$ and HCHO treated $\left(\mathrm{T}_{3}\right)$ concentrate mixture with 2 per cent added urea and 70:30 untreated $\left(\mathrm{T}_{4}\right)$ and HCHO treated $\left(\mathrm{T}_{5}\right)$ concentrate mixture with 3 per cent added urea supplementation diets, respectively. Per cent BW DMI under different treatments clearly indicated that the cows received sufficient DM to fulfill the appetite and consequently supply of nutrients to the body. The unit body size intake of all the cows met out the nutritional standards of $2.5 \mathrm{~kg} \mathrm{DM} / 100 \mathrm{~kg}$ body weight. Hence, it seems no reason to consider the adverse effect of feeding formaldehyde treated $(1.5 \mathrm{~g} / 100 \mathrm{~g} \mathrm{CP})$ concentrate with added urea ration to cows in reference to express their optimum performance.

KEY WORDS...... Formaldehyde, Sugras, Urea, Soybean meal, Proximate analysis, Feed intake, Dry matter intake

HOW TO CITE THIS ARTICLE - Chore, N. S., Chavan, S. D., Shelke, R. R. and Nage, S. P. (2017). Effect of formaldehyde treated concentrate, urea and soybean meal on proximate analysis and feed intake in lactating cows. Asian J. Animal Sci.,12(1): 22-28. DOI : 10.15740/HAS/TAJAS/12.1/22-28.

ARTICLE CHRONICLE - Received : 19.04.2017; Revised : 05.05.2017; Accepted : 18.05.2017 